\title{
A Anforologia - uma nova disciplina arqueológica
}

\section{Pedro Paulo Abreu Funari}

Departamento de História, UNESP (Assis)

\section{INTRODUÇÃO}

A anforologia, difinindo-se como um setor específico de estudo arqueológico, apresenta três níveis de concretização, necessários para a delimitação de qualquer disciplina. Em primeiro lugar, um objeto de pesquisa determinado: as ânforas. Em seguida, o estudo desse objeto em um lugar específico de produção científica, implicando um meio de elaboração circunscrito por determinaçães próprias. Por fim, e em função desse lugar, instaura-se uma prática específica de produção de conhecimento. Nosso objetivo, neste trabalho, é apresentar, nos três níveis citados, a especificidade da anforologia como uma disciplina na arqueologia clássica. (1)

\section{A CONSTITUIÇÃO DO OBJETO}

A ânfora, como objeto de estudo da anforologia, é uma parte da documentação material delimitada pelos critérios da própria disciplina. A ânfora define-se, primeiramente, como um vaso-recipiente cerâmico, destinado à armazenagem e, principalmente, ao transporte de produtos líquidos à longa distância. Como decorrência de tal definição, podemos delimitar suas características formais essenciais: a presença de duas alças verticais

(1) - Este trabalho foi originalmente apresentado ao VII Encontro de História do Núcleo Regional de São Paulo da ANPUH em setembro de 1984. Este estudo é parte de uma pesquisa que contou com $O$ apoio financeiro do Conselho Nacional de Desenvolvimento Científico e Tecnológico (CNPq) e da Fundação de Amparo à Pesquisa do Estado de.São Paulo (FAPESP). Agradecemos aos professores André Tchernia, Emílio Rodríguez-Almeida, Clementina Panella, José Remesal, Daniele Manacorda e Monique Clavel-Lévêque, que de várias formas ajudaram na elaboração deste trabalho. 
(2) - como o próprio nome já indica, amphi + phero - que permitem o fácil transporte do vaso, e o colo estreito, que permite o lacramento da ânfora, evitando o transbordamento do conteúdo transportado. As demais características formais do vaso, por serem inessenciais à sua função, não participam da definição básica da ânfora, podendo dar origem a uma grande variabilidade de formas.

O objeto de estudo "ânfora", portanto, não é dado ao conhecimento, mas construído através de critérios estabelecidos pela própria disciplina. Nesse sentido, o conceito de ânfora para a anforologia, ao restringir-se ao vaso-recipiente, não abrange a ânfora mercadoria, em geral decorada, portadora de valor intrínseco (3). Os estudos de temas iconográficos que têm por suporte ânforas, não se referem ao mesmo objeto, nem utilizam a mesma prática metodológica da anforologia.

\section{A PRODUÇÃO DO CONHECIMENTO DA ANFOROLOGIA}

A existência de um lugar de produção científica para o estudo das ânforas, tal como se apresenta atualmente, é resultado da evolução da pesquisa anfórica dentro da Arqueologia clássica. Assim, antes de explicitar a configuração atual dos estudos anfóricos, impõe-se uma referência aos momentos de constituição da disciplina. Distinguimos três fases no estudo das ânforas: uma primeira etapa, pré-disciplinar, em que o objeto de estudo ainda não estava plenamente especificado e delimitado; uma segunda etapa, proto-disciplinar, em que o objeto adquiriu autonomia, iniciando-se a instituição de um lugar de produção científica e de uma metodologia específicas e, por fim, a plena constituição da anforologia enquanto disciplina da arqueologia clássica, caracterizada por uma explicitação de sua autonomia nos trề níveis de sua manifestação: no objeto, na sua institucionalização acadêmica e na metodologia própria.

O estudo das ânforas surgiu nas décadas finais do século XIX, como subproduto dos estudos de epigrafia grega e latina. Na verdade, desde o

(2) - Desde meados de década de 1960 (Zevi, F., "Appunti sulle anfore romance", Archeologia Classica, 27, 1966: 208-247, retomando as considerações de Loeschke, S., "Das römische und belgische Keramik", in: Albrecht, Ch. Das Römerlager in Oberaden. Dortmund, 1942) e, especialmente na última década (Hamon, E. \& Hesnard, A., "Problèmes de documentation et de description relatifs à un corpus d'amphores romaines". in: Méthodes Classiques et métodes formelles, dans l'étude des amphores. Paris, de Boccard, 1977: 17-33), tem-se discutido o conceito de "ânfora", tanto no contexto da tradição textual como na própria literatura arqueológica. Para uma discusão e bibliografia atualizadas a esse respeito veja-se nosso trabalho a ser publicado nas Atas do I Congresso Nacional de Estudos Clássicos, Belo Horizonte, 1984 ("Em torno da ânfora, a terminologia latina dos vasos recipientes").

(3) - Vallet, G. \& Villard, F., "Céramique Grecque et Histoire Économique", in: Courbin, P. (org.), Etudes Archéologiques. Paris, SEUPEU, 1963: 205-217. 
século anterior alguns italianos como Ficorini (Le vestigia e rarità di Roma antica, 1744 e Eschinardi (Descrizione di Roma e dell'agro romano, 1750), haviam descrito as ânforas encontradas, em grande quantidade, em Roma. No entanto, apenas com Theodor Mommsen e seu projeto de edição do Corpus Inscriptionum Latinarum (CIL), a partir de 1863, começou-se a pensar nas ânforas como vasos portadores de inscrições, selos e tituli picti, que tinham ânforas como suporte. A descrição da forma das ânforas era sumária e sempre referível a tipos abstratos e genéricos, não a exemplares individuais. Surgiram dessa forma as primeiras tábuas tipológicas (MAU - CIL IV -; SCHÖNE - CIL IV -; DRESSEL - CIL XV, 2), que tinham por objetivo a atribuição das inscrições - o verdadeiro objeto de estudo (4) - a uma forma cerâmica genérica. As tábuas tipológicas, em geral pouco objetivas, evidenciavam o descuido para com as ânforas em si, fato revelado igualmente pela destruição e não publicação do material anepigráfico, certamente majoritário.

Neste período inicial, o pesquisador alemã.o Dressel, encarregado por Mommsen da publicação do volume XV, 2, do $C I L$, referente ao instrumentum domesticum da cidade de Roma, iniciou um estudo que ultrapassava os limites da epigrafia latina em geral. Podemos considerá-lo o fundador do estudo científico das ânforas, pois, a partir de uma preocupação com a sistemática das inscrições anfóricas, desenvolveu sua pesquisa em dois sentidos especificamente anfóricos: em primeiro lugar, delimitou uma epigrafia particular, com mecanismos próprios e cuja pesquisa inaugurou a epigrafia anfórica (5). Em seguida, e como decorrência dessa preocupação, elaborou uma tipologia anfórica (6), baseada em critérios formais, que viria a ser a base da compreensão dos mecanismos de diferenciação dos tipos de ânforas e, portanto, dos conteúdos transportados.

Esta primeira fase foi assim caracterizada pelo surgimento do objeto de pesquisa - a ânfora. Contudo, após as pesquisas de Dressel, os estudos anfóricos praticamente se eclipsaram até meados de nosso século. Tal fato deveu-se a diversos fatores, dos quais dois foram seguramente determinantes. Em primeiro lugar, a não constituição de um lugar de produção científica institucionalizado, que pudesse dar continuidade ao trabalho individual de Dressel. Essa ausência era resultado, por sua parte, do eclipse da

(4) - Sobre a especificidade do estudo das inscriçōes anfóricas e, em particular, sobre seu desenvolvimento na última década veja-se Funari, P.P.A., "As evidências da Epigrafia Anforária: especificidades e características", Resumos da 37. ${ }^{\text {a }}$ Reunião Anual da SBPC, Ciência e Cultura, Suplemento, 7, 37, 1985: 147-148.

(5) - Dressel, H. Saggi sull'intrumentum romano. Roma, E.U. Coop., 1978: 132-174.

(6) - Id., Ibidem: tav. 7-8; Id.,Inscriptiones Urbis Romae Latinae. Berlim, Akademie Verlag, 1899: Tab. 1. 
escola neo-humanista de Mommsen, desde os primeiros anos do século XX, submersa pelo ambiente cultural europeu em rápida mudança, em especial no período entre guerras (7). Apesar de os estudos do arqueólogo soviético B. N. Grakov sobre os selos anfóricos gregos iniciarem ainda em fins da década de 1920, sua fundamental obra Recipientes cerâmicos timbrados do periodo helenístico como fonte para a história da produção e do comércio (1939) permanece inédita, embora freqüentemente citada por outros autores soviéiicos (8). De qualquer forma as décadas de 1940 e 1950 assinalam o reaparecimento, na pesquisa arqueológica, do objeto de estudo "ânfora". Seu ressurgimento dá-se, de início, no contexto de estudos tipológicos ainda pouco desenvolvidos, prevalecendo uma concepção da cultura material que não dava conta do conteúdo sociológicu do artefato ânfora (9), e que não percebia o imenso potencial de informações proporcionado por este vaso-recipiente de transporte (10). No entanto o estudo da epigrafia anfórica permitiu um redirecionamento das pesquisas no sentido de uma recuperação da unidade entre a forma do vaso e seu conteúdo. Assim, Virgínia Grace (11) iniciou o estudo dos selos anfóricos gregos, enquanto Emile Thouvenot (12) e Robert Etienne (13) voltavam-se para a análise da epigrafia das ânforas romanas e Nino Lamboglia (14) e François

(7) - Vejam-se as considerações de Rodríguez-Almeida, E., "Heinrich Dressel", in: Dressel, H.,Saggi: 1 e de Zevi, F., op. cit.: 209.

(8) - Braschinsky, J.B., "The Progress of Greek Ceramic Epigraphy in the USSR", Eirene, 1973: 117.

(9) - Particularmente significativas a esse respeito são as classificações de Pelichet, E., “A Propos des Amphores Romaines trouvées à Nyon", Zeitschrift für schweizerisch Archäologie und Kunstgeschichte, 8, 1946: 189-209 e de Almagro, M., Las necropolis punicas, griegas y romanas, Barcelona 1955. A primeira, ao seccionar o artefato, estabelece tipologias cronológicas de partes isoladas das ânforas - em especial do lábio - não havendo em consideração a unidade forma/conteúdo, essencial no estudo das ânforas. A segunda, ao acrescentar à tipologia de Dressel doze formas, sem levar em consideração a proveniência e datação das peças, demonstra, ainda uma vez, o caráter prematuro dessas classificaçōes.

(10) - Assim, Goodchild escrevia em 1951, a respeito de fornos cerâmicos produtores de ânforas que "a cerâmica produzida nos sítios de Gebel não pussui características que possam estimular grande interesse arqueológico (apud Manacorda, D., "Prosopografia e anfore Tripolitane: nuove osservazioni", in: II Congreso del Aceite en la Antigüedad. Madri, Universidad Complutense, 1984: 483).

(11) - Grace, V., "Timbres Amphoriques: Délos", Bulletin de Correspondance Hellénique, 76, 1952: 514-540.

(12 - Thouvenot. E., "Una familia de negociantes en aceite establecida en la Bética en el siglo II: los Aelli Optati”, Archivo Español de Arqueologia, 25, 1952: 225-231.

(13) - Etienne, R., "Les amphores du Testaccio au IIIe siècle", Mélanges de l'École Française de Rome, 61, 1949: 151-181.

(14) - Lamboglia, N., "Sulla cronologia delle anfore romane", Rivista di Studi Liguri, 21, 1955: 53-78. 
Benoit (15) iniciavam o estudo do próprio artefato cerâmico. Estas pesquisas permitiram a passagem do estudo das inscrições para seu suporte - as ânforas. Assim, nos anos 1960, multiplicaram-se os pesquisadores que se voltavam para o material anfórico.

Estes arqueólogos, entretanto, não tinham o estudo das ânforas como sua especialidade, o que era decorrência da inexistência de institucionalização da pesquisa anfórica em um lugar de produção científica particular e do desenvolvimento de uma metodologia própria. Em 1966, Fausto Zevi, em um artigo sobre a tábua tipológica de Dressel, colocou em questão os critérios utilizados para o estudo do material anfórico romano e abriu uma nova etapa da anforologia, caracterizada pelo surgimento embrionário de uma nova especialização acadêmica. Os arqueólogos atuantes nesse período, em particular F. Zevi (16) e André Tchernia (17), contribuíram para a formação dos primeiros anforólogos, os quais, no início da década de 1970 , viriam a estabelecer os fundamentos da moderna pesquisa anfórica, abrindo espaço para o seu desenvolvimento, a nível de ensino e pesquisa, nas instituiçōes às quais estavam ligados. Surgiram, assim, formal ou informalmente, os setores de anforologia de instituições como a École Française de Rome (18), a École Française d'Athènes (19) e, particularmente, institutos como o Centre Camille Jullien (20), o Centre Pierre Paris (21), Universidade de Madri (22), Universidade de Roma (23), entre outros.

(15) - Benoit, F., L'Épave du Grand-Congloué à Marseille. Paris, 1961; Idem, "Relations commerciales entre le Monde Ibéro-Punique et le Midi de la Gaule, de l'époque archaïque à l'époque romaine", Revue des Etudes Anciennes, 68, 1961: $322-331$.

(16) - Zevi, F., op. cit.

(17) - Tchernia, A., "Amphores et Marques d' Amphores de Bétique à Pompéi et Stabies", Mélanges de l'École Française de Rome, 1964: 419-455; Idem, "Les amphores romaines et 1' histoire économique",Journal des Savants, 1967: 216-234.

(18) - Principalmente na organização de colóauios como Recherches sur les Amphores Romaines, Roma, Ecole Française, 1972 e Méthodes Classiques et Méthodes Formelles dans l'Etude des Amphores. Paris, de Boccard, 1977.

(19) - Cf. Empereur, J.Y., "Les Anses d'Amphores Timbrées et les Amphores: aspects quantitatifs", Bulletin de Correspondance Hellénique, 106, 1982: 514-540 e Garlan, Y., "Le Commerce des Amphores Crecques", Eighth International Economic History Congress. Budapeste, Akademiai Kiado, 1982: 52-60.

(20) - Tchernia, A., "Quelques Remarques sur le Commerce du Vin et les Amphores", Memoirs of the American Academy in Rome, 36, 1980: 305-312.

(21) - Colls, D. et alii, "L’Épave Port-Vendres II et le Commerce de la Bétique à l'èpoque de Claude", Archaeonautica, 1, 1977.

(22) - Remesal, J., "Transformaciones en la exportación del aceite bético a mediados de siglo III d.C.", II Congreso del Aceite en la Antigüedad. Madri, Universidad Complutense, 1984: 115-131.

(23) - Panella, Cl., "I contenitori oleari presenti ad Ostia in età antonina: analisi tipologica, epigrafica, quantitativa”, II Congreso del Aceite en la Antigüedad. Madri, Universidad Complutense, 1984: 227-291. 


\section{DIMENSÃO METODOLOGICA}

Essa institucionalização da disciplina foi acompanhada do desenvolvimento paralelo de uma metodologia própria. A questão metodológica pode ser abordada em dois níveis distintos: em primeiro lugar, desde a década de 1960 manifesta-se uma preocupação na arqueologia clássica pelo estudo do objeto seriado, da pluralidade de artefatos que constituem tipos. Essa mudança de perspectiva relaciona-se com a valorização do objeto comum, de uso cotidiano, utilizado em larga escala, geralmente anepigráfico e de escasso valor intrínseco. Assim, a ênfase no estudo do instrumentum domesticum deriva de uma transformação epistemológica - a preocupação com o estudo da série e da tendência (24) - e evidencia um deslocamento do eixo de reflexão sobre as sociedades antigas. $\mathrm{O}$ objeto de arte, único e original, liga-se, inevitavelmente, à prática de um grupo social restrito; por outro lado, o instrumentum domesticum, ou seja, os objetos de uso quotidiano de largas camadas sociais, constitui-se num instrumento privilegiado de aproximação a realidades sociais que estavam além do alcance da pesquisa arqueológica e histórica.

No caso específico das ânforas - um dos componentes do instrumentum domesticum - a valorização do vaso-recipiente possibilitou ao pesquisador o conhecimento de práticas sociais extendidas, ligadas à produção e consumo de vinho, azeite e salmouras, que representavam as produções mais dinâmicas da economia antiga. Isto tornou possível a introdução de uma nova problemática, ligada ao estudo da produção de valores-de-troca na Antiguiidade. Atualmente, diversos estudiosos e grupos de pesquisa têmse dedicado ao estudo da extensão do capital mercantil no mundo clássico e ao relacionamento entre os setores produtores de valores-de-troca e as áreas onde predominava o valor-de-uso, possibilitando uma redefinição de conceitos como modo-de-produção escravista, exceção dominante, articulação de diferentes modos-de-produção e assim por diante (25). Nesse sentido,

(24) - Carandini, A., Archeologia e Cultura Materiale. Bari, De Donato, 1979: 20; Meneses, U.T.B., "A Cultura Material no Estudo das Sociedades Antigas", Revista de Historia, 115, 1983:112.

(25) - Sobre tais questôes vejam-se os estudos recentes de Carandini, A., "Roma imperialistica: un caso di sviluppo precapitalistico", Memoirs of the American Academy in Rome, 36, 1980: 11-19; Corbier, M., "Proprietà e gestione della terra: grande proprietà fondiaria ed economia contadina", in: Sociedatà Romana e Produzione Schiavistica I. Roma, Laterza, 1981: 427-444; Dyson. S., "New Methods and Models in the Study of Roman Town-Country Systems", The Ancient World, 2, 1979: 97-103; Ekholm, K. \& Friedman, J., "Capital, Imperialism and Exploitation in Ancient-World System", Review, 1982: 87-127; Lepore, E., "Geografia del modo 
os estudos anforológicos têm sido amplamente patrocinados pelo Instituto Gramsci (26), pela American Academy in Rome (27) e por outros grupos de pesquisa e instituições.

Contudo, para que a ânfora possa tornar-se uma evidência da vida social e econômica do homem antigo, a anforologia deve possuir uma metodologia própria, que dê conta do caráter seriado, uniforme e típico da produção anfórica. A anforologia desenvolveu, assim, duas grandes linhas de abordagem do material à sua disposição, ambas tendo como base a tipologia, entendida como o estudo do artefato individual dentro de uma série. Desenvolveu-se, por outro lado, o estudo tipológico das inscrições anfóricas. Este setor de conhecimento inter-disciplinar - epigráfico e ceramológico - tem chegado, através do estudo sistemático das inscriçōes, a uma precisão de leitura que ultrapassa os limites tradicionais da epigrafia aplicada às ânforas. Assim, o arqueólogo espanhol E. Rodriguez-Almeida, pela observação e análise dos tituli picti em ânforas de tipo Dressel 20, pôde determinar não apenas uma evolução cronológica específica de tais inscrições como identificar, com precisão, caligrafias locais, permitindo diferenciar a origem de ânforas produzidas numa mesma região, o vale do rio Guadalquivir, na Espanha Meridional, mas em olarias localizadas em cidades diferentes. Isto só foi possível pela presença de uma série de epígrafes, que permitiram o estudo global, tipológico, das inscrições.

Em um segundo nível, a tipologia formal tem-se desenvolvido, recentemente, através de duas perspectivas diversas. A tipologia tradicional caracteriza-se pela segmentação simples do vaso, pela valorização de diferenças formais e pela análise da argila e do engobo a olho nu; trata-se de um

di produzione schiavistico e modi residui in Italia Meridionale", in: Società Romana $e$ Produzione Schiavistica I. Roma, Laterza, 1981: 3-54; Manacorda, D., "L'ager cosanus tra tarda Repubblica e Impero; forme di produzione e assetto della proprietà", Memoirs of the American Academy in Rome, 36, 1980: 173-184; Musti, D., "Per una ricerca sul valore di scambio nel modo di produzione schiavistico", in: Analisi Marxista e Società Antiche. Roma, Riuniti, 1978: 147-175; Sciavone, A., "Per una rilettura delle Formen: teoria della storia, dominio del valore d'uso e funzione dell'ideologia", in: Analisi Marxista e Società Antiche. Roma, Riuniti, 1978: 75-107.

(26) - Manacorda, D., "Produzione agricola, produzione ceramica e proprietà nell'ager consanus nel I secolo a.C.”, in: Società Romana e Produzione Schiavistica II. Roma, Laterza, 1981: 3-54; Panella, Cl., "Il vino: la distribuzione e i mercati", in: Società Romana e Produzione Schiavistica II. Roma, Laterza, 1981: 55-80; Manacorda, D. "Produzione agricola".

(27) - Manacorda, D., "L'ager cosanus"; Rodríguez-Almeida, E., "Vicissitudine nella gestione del commercio dell'olio betico da Vespasiano a Severo Alessandro", Memoirs of the American Academy in Rome, 36, 1980: 277-290; Tchernia, A., "Quelques remarques". 
conhecimento empático e subjetivo do artefato. A própria transmissão do "saber classificatório" por parte do arqueólogo torna-se uma operação complexa, por vezes mal-sucedida (28). Uma concepção bastante difusa tende a interpretar a evolução do artefato como análogo ao ciclo biológico. Nessa visão vitalista ou ontogenética da cultura material, o artefato adquire vida própria, com nascimento, apogeu e morte, independente dos homens que, como produtores e utilizadores, relacionaram-se com ele em seu quotidiano (29).

Por outro lado, uma manipulação informatizada do material desenvolveu-se nos último anos, com a introdução de métodos formais, ou seja, numéricos, de descrição e seccionamento das ânforas. Esses estudos têm sido amplamente desenvolvidos na França, onde os programas de informatização em arqueologia estão-se generalizando. Dessa forma, o grande número de ânforas que constituem os corpora tipológicos pode ser utilizado através do recurso do computador, propiciando o armazenamento de grande quantidade de material. A utilização de técnicas de informatização para o estabelecimento de tipologias, contudo, implica numa abordagem específica do material anforário, um modus cognoscendi que se distancia do produtor e consumidor das ânforas, ao basear-se em relações meramente numéricas entre as diferentes partes do vaso. Os seccionamentos assim realizados pelos pesquisadores nas ânforas não são perceptíveis ao olho humano, e não podem, desa forma, revelar padrões que fossem significativos para os usuários. Alguns estudos nesse campo têm ressaltado essa limitação do método formal, sua incapacidade de revelar uma tipologia relevante para a compreensão das formas de utilização do objeto ânfora.

Ambas as abordagens, embora tenham contribuído para um melhor conhecimento dos tipos anfóricos nas últimas duas décadas, demonstraram serem incapazes de enfrentar a profusão de dados acumulados neste lapso de tempo. A presença, em um mesmo sítio, de dezenas de formas anfóricas diversas, cuja origem, difusão e diferenciação morfológica apresentam-se incertas, conduziu, ao mesmo tempo, a um agrupamento de tipos (DRESSEL 7-11; DRESSEL 2-4) e, inversamente, à crescente subdivisão dos mesmos (BELTRAN I, II, III, IV; DRESSEL 23 A, 23 B, EL TEJARILLO 1, 2 e 3; DRESSEL 6 A e B). Estas classificações, aida que muito tenham contribuído para o conhecimento dos tipos anfóricos, pouco esclareceram sobre os motivos e as características das transformações formais de cada tipo em particular e do conjunto das ânforas.

(28) - Tchernia, A., "Intervention", in: Méthodes Classiques et Méthodes Formelles dans l'étude des Amphores. Paris, De Boccard, 1977: 287-288.

(29) - Clarke, D. L., Analytical Archeology. Londres, Methuen, 1968. 
Esta "crise da adolescência" da anforologia, por sua parte, envolve, para sua superação, uma reflexão sobre a própria definição do objeto de estudo da disciplina. Ao definir-se como vaso-recipiente de transporte, a ânfora torna-se um objeto cuja característica peculiar é a transmissão, através de sua forma, de uma mensagem referente, diretamente, a seu conteúdo; sua função conotativa associa-se intimamente à sua função denotativa. Assim, para o usuário comum, a mensagem pode resumir-se a um enunciado básico sobre o conteúdo, tal como "recipiente para vinho, azeite ou molho de peixe". Contudo, a nível do comerciante, ou do agente estatal, por exemplo, essa mensagem torna-se mais precisa, fornecendo informações sobre a auantidade e qualidade do líquido transportado, sobre a região produtora ou sobre a data de fabricação. A necessidade de que a men. sagem seja compreendida deriva da grande quantidade e variedade de ânforas e produtos transportados e comercializados numa mesma região, tornando imperativo a identificação dos conteúdos e das zonas produtoras.

A mensagem de cada ânfora, portanto, só pode definir-se dentro de um código constituído por um sistema anfórico sincrônico, que estabelece oposições binárias de forma e sentido entre os tipos. Não basta à anforologia estabelecer tábuas tipológicas, sincrônicas e com proveniências idênticas das ânforas, assim como não é suficiente reconhecer a ligação forma/ conteúdo deste artefato cerâmico (30). Apenas com o estudo de códigos anfóricos sucessivos no tempo, com o controle dos níveis de difusão de artefatos e, portanto, de mensagens, a anforologia poderá compreender os agentes da transformação morfológica das formas anfóricas. Dessa maneira, pode-se recuperar o elo artefato/realidade sociológica, considerando-o não apenas como índice de relações sociais, mas também como vetor destas (31). A abordagem semiológica implica a existência não apenas do oleiro e de seu produto, como a interação entre estes dois e o consumidor e usuário. A partir desta perspectiva, contando com uma abordagem que dá conta da especificidade de seu objeto, a anforologia pode encaminhar-se para a superação de sua primeira crise de crescimento.

\section{CONCLUSÃO}

Retornando à nosa formulação original, vemos que a anforologia, ou seja, o logos, discurso ou conhecimento sobre as ânforas, possui as premissas básicas para se definir como disciplina da Arqueologia Clássica: constrói seu próprio objeto, possui um lugar de atuação científica determi-

(30) - Tal relação, proposta já há duas décadas por Tchernia ("Amphores et Marques": 443), tem suscitado um vivo debate entre os anforólogos, que contudo foge ao escopo deste artigo.

(31) - Meneses, U. T. B., "A Cultura Material": 113. 
nado institucionalmente e uma prática específica de produção de conhecimento. Ao despojar-se de sua espontaneidade original, o termo anforologia, surgido da própria prática dos arqueólogos que se dedicaram ao estudo da ânfora, explicita-se como disciplina quando o pesquisador volta seu discurso para sua própria atividade científica. 